\title{
Late morbidity after treatment of breast cancer in relation to daily activities and quality of life: a systematic review
}

\author{
J. S. Rietman*§, P. U. Dijkstra*§, H. J. Hoekstrał, W. H. Eisma*§, \\ B. G. Szabo $\ddagger$ J. W. Groothoff§ and J. H. B. Geertzen*§
}

\begin{abstract}
Departments of *Rehabilitation Medicine, †Surgery and $¥$ Radiotherapy, University Hospital Groningen, P.O. Box 3000I, NL-9700 RB Groningen, The Netherlands and §Northern Centre for Health Care Research, University of Groningen, A. Deusinglaan I, NL-97। 3 AV Groningen, The Netherlands
\end{abstract}

\begin{abstract}
Aims: Breast cancer treatment may result in long-term upper limb morbidity: reduced range of motion of the shoulder, muscle weakness of the arm and hand, lymph edema, pain and numbness. Relationship of this late morbidity with activities of daily life $(A D L)$ and quality of life $(\mathrm{QOL})$ is infrequently described and the strength of this relationship is not clear.

Methods: A systematic review was performed to evaluate the results of studies, analyzing late morbidity of breast cancer treatment in relationship with ADL and/or QOL. A literature search over the last 20 years (1980-2000) was performed in the databases MEDLINE, EMBASE, PSYCHLIT and CANCERLIT. Methodological quality of selected articles was assessed and additional, aspects of treatment related late morbidity and the relationship to ADL and/or QOL were summarized.

Results: From the 1642 yielded articles 15 fulfilled our primary selection criteria. Only six articles could be selected due to the inappropriate methodological quality. There was high variation in prevalence of pain (12-5I\%), impairments in range of motion (2-5I\%), edema (6-43\%) and decreased muscle strength (17-33\%). Four articles reported significant relationships between late morbidity of the upper limb and perceived disabilities in ADL/QOL. The strength of these relationships was rather low.

Conclusions: Few studies investigated the relationship between late morbidity of the upper limb after treatment of early breast cancer and ADL/QOL. Significant relationship between late morbidity and restrictions of daily activities and poorer QOL was reported, however, the strength of this relationship was rather low.
\end{abstract}

(c) 2002 Elsevier Science Ltd. All rights reserved.

Key words: breast cancer; late morbidity; range of motion; lymph edema; activities of daily life; quality of life.

\section{INTRODUCTION}

The incidence of breast cancer in the Netherlands is $100 / 100000$ women per year.' One out of nine women will develop breast cancer, of which $79 \%$ will survive at least 5 years. ${ }^{1-3}$ The aim of breast cancer treatment is to obtain maximal locoregional control, optimal lymph node staging with minimal treatment related morbidity, good functional result and when possible preservation of the breast.

Halsted introduced in 1894 the radical mastectomy in the treatment of breast cancer. ${ }^{4}$ The radical mastectomy

Correspondence to: Johan S. Rietman, MD, University Hospital Groningen, Department of Rehabilitation Medicine, P.O. Box 3000I, NL-9700 RB Groningen, The Netherlands. Tel: +3I 503612295 ; Fax: +3l 5036 I I708; E-mail: j.s.rietman@rev.azg.nl was associated with extensive upper limb morbidity including impairments such as reduced range of motion of the shoulder, muscle weakness of the arm and hand, lymph edema, pain and numbness. ${ }^{5-8}$ Fortunately, these impairments have become less common as the radical mastectomy has been replaced by the modified radical mastectomy in which the pectoralis muscles were preserved. $^{7,9-13}$ Breast conserving treatment, consisted of local tumor excision and adjuvant radiation treatment of the breast, was introduced for early breast cancer in the sixties and further developed in the seventies and eighties. ${ }^{14-20}$ However, these less extensive procedures still resulted in upper limb morbidity in a considerable amount of patients. ${ }^{21-24}$

The axillary lymph node status is the most significant prognostic variable in patients with breast cancer. ${ }^{25,26}$ Axillary lymph node dissection is therefore an important 
diagnostic and treatment procedure. ${ }^{27}$ This dissection may also result in long-term upper limb morbidity. $6,8,24,27-31$ Recently the sentinel node procedure was introduced to reduce the number of unnecessary axillary lymph node dissections, and thereby reducing treatment morbidity from a complete axillary lymph node dissection. ${ }^{32-35}$

Additional radiation therapy of the axilla may increase upper limb morbidity due to late normal tissue radiation injury. ${ }^{6,23,30,36-41}$ The appearance of this type of injury dictated a stepwise reduction in radiation dose and increasing fractionation throughout the sixties. ${ }^{21,22}$ Since the early seventies the standard treatment policy of radiation therapy is a moderate doses (50 Gy) to the breast and locoregional lymph drainage area such as axilla and supraclavicular, with higher doses directed only to the tumor bed. ${ }^{21}$ Radiation therapy only to the breast did not increase incidence of upper limb morbidity. ${ }^{28}$

The incidence of late morbidity after breast cancer treatment: arm edema and reduced range of motion of the shoulder, varies widely due to differences in study population, surgical procedures, radiation dose and fractionation and assessment methods.

Late morbidity may interfere with activities of daily life (ADL) and quality of life (QOL). ${ }^{42-44}$ However, it is not clear how strong the relationship is between late morbidity (pain, edema, restriction of range of motion and muscle weakness) and ADL and QOL. This systematic review was performed to evaluate the results of studies, analyzing late morbidity of breast cancer treatment in relationship with ADL and/or QOL.

\section{METHODS}

\section{Literature search}

The search for relevant publications in the literature over the last 20 years (1980-2000) was performed in the databases MEDLINE, EMBASE, PSYCHLIT and CANCERLIT. Three sections of mesh headings were used. The first section contained the mesh headings 'breast cancer' or 'mastectomy'. The second section contained 'physical examination', 'edema', 'lymph edema', 'paresthesia', 'arm', 'morbidity' or 'ADL'. Mesh headings in the third section were 'QOL', 'follow up', 'treatment outcome', 'rehabilitation', 'disability evaluation', 'prospective studies', 'functional assessment' or 'assessment'. Additional words such as 'functional', 'sensation', 'fractionation', 'conserving' were searched in the title of the publications. Finally the three sections were connected to each other. No language restriction was applied. The abstracts of publications found were screened and selected by the first author (JR) on the basis of the following criteria:

I. the patients must have early breast cancer, defined as a clinical stage I $\left(\mathrm{p} \mathrm{T}_{1} \mathrm{~N}_{0} \mathrm{M}_{0}\right)$ or II $\left(\mathrm{pT}_{1,2,3} \mathrm{~N}_{0,1} \mathrm{M}_{0}\right)$,
2. the treatment modalities studied, must either be a modified radical mastectomy or breast conserving surgery alone or in combination with radiotherapy and/or chemotherapy,

3. late morbidity of the locomotor system must be studied with an interval of minimal one year after the surgical treatment,

4. the relationship of this late morbidity with $A D L$ and/or factors of QOL must be investigated.

Lastly, the reference list of the selected articles generated by the search and the screening were searched for articles not found by the computer. Excluded were case reports, pilot studies and abstracts.

\section{Critical review}

The quality of the selected articles was assessed by using a checklist of 30 items concerning general methodological aspects of the studies and the assessment tools used (Appendix I). The greater part of the checklist (items 13-29) was related to the application of measurement instruments and the description of their reliability and validity. Reference articles cited by the authors in relation to reliability and validity of the measurement instruments were retrieved and also assessed according to the same criteria.

The criteria were scored on a dichotomous scale: score ' $I$ ' if the criterion was met and ' 0 ' if the criterion was not met. Two reviewers (JG, PD) independently assessed all the selected articles. In a consensus meeting the scores of the two reviewers were compared. As a measure of interobserver agreement Cohen's Kappa was calculated. When there was disagreement in the assessment score, consensus was reached by means of discussion. In cases of persistent disagreement a third reviewer (JR) gave the final judgment.

In addition to the methodological assessment of the articles (Table I), aspects of treatment related late morbidity and the relationship of this late morbidity to ADL and/or QOL were summarized (Table 2).

\section{RESULTS}

The literature search yielded 2127 articles of which 485 articles were double registered thus 1642 articles remained. From the 1642 articles 15 fulfilled the previous described selection criteria. ${ }^{30,39,4 I, 43-54}$ Another $3 \mathrm{I}$ reference articles were retrieved necessary for assessment of the methodological criteria.

Cohen's Kappa was 0.88 . In all scores a consensus was met. Seven items (items 6, 18, 20, 24, 26-28) of the criteria list scored constant. After exclusion of these seven items from the calculation, the Cohen's Kappa was 0.87 .

In Table I the consensus score for each article is presented. The maximum score that could be obtained 


\begin{tabular}{|c|c|c|c|c|c|c|c|c|c|c|c|c|c|c|c|c|c|}
\hline Study & & $\begin{array}{c}\text { Swedborg } \\
1981^{43}\end{array}$ & $\begin{array}{l}\text { Aitken } \\
1989^{39}\end{array}$ & $\begin{array}{c}\text { Bentzen } \\
1989^{30}\end{array}$ & $\begin{array}{l}\text { Hamilton } \\
1990^{45}\end{array}$ & $\begin{array}{c}\text { Segerström } \\
|99|^{46}\end{array}$ & $\begin{array}{l}\text { Ivens } \\
1992^{48}\end{array}$ & $\begin{array}{c}\text { Maunsell } \\
1992^{49}\end{array}$ & $\begin{array}{l}\text { Sneeuw } \\
1992^{47}\end{array}$ & $\begin{array}{l}\text { Tobin } \\
1993^{44}\end{array}$ & $\begin{array}{c}\text { Tasmuth } \\
1996^{50}\end{array}$ & $\begin{array}{c}\text { Carpenter } \\
1998^{51}\end{array}$ & $\begin{array}{l}\text { Warmuth } \\
1998^{52}\end{array}$ & $\begin{array}{l}\text { Sugden } \\
1998^{41}\end{array}$ & $\begin{array}{c}\text { Velanovic } \\
1999^{53}\end{array}$ & $\begin{array}{l}\text { Hack } \\
1999^{54}\end{array}$ & Total \\
\hline \multirow[t]{2}{*}{ Study population } & 1 & 1 & 1 & - & 1 & I & 1 & I & 1 & I & I & 1 & I & I & 1 & I & 14 \\
\hline & 2 & 1 & - & 1 & - & - & - & 1 & - & - & - & 1 & - & - & - & - & 4 \\
\hline \multirow[t]{3}{*}{ Study design } & 3 & - & - & - & - & I & - & 1 & - & - & 1 & - & - & I & 1 & - & 5 \\
\hline & 4 & - & - & - & - & I & - & I & - & - & I & - & - & I & - & - & 4 \\
\hline & 5 & 1 & 1 & - & - & - & - & - & - & - & - & - & - & - & - & - & 2 \\
\hline \multirow[t]{2}{*}{ Allocation procedure } & 6 & - & - & - & - & - & - & - & - & - & - & - & - & - & - & - & 0 \\
\hline & 7 & 1 & I & I & - & - & - & 1 & - & I & - & - & I & I & 1 & I & 9 \\
\hline \multirow[t]{2}{*}{ Treatment description } & 8 & 1 & 1 & 1 & 1 & 1 & - & - & 1 & - & 1 & - & 1 & I & - & 1 & 10 \\
\hline & 9 & 1 & 1 & 1 & 1 & 1 & - & - & I & - & - & - & - & 1 & - & - & 7 \\
\hline Dropouts & 10 & I & - & - & 1 & 1 & - & I & I & 1 & I & I & 1 & - & I & & 11 \\
\hline $\begin{array}{l}\text { Baseline } \\
\text { measurement }\end{array}$ & 11 & - & - & - & - & - & - & - & - & - & 1 & - & - & I & - & - & 2 \\
\hline \multirow{6}{*}{$\begin{array}{l}\text { Measurement } \\
\text { instruments }\end{array}$} & 12 & - & 1 & - & - & - & 1 & 1 & - & - & - & - & 1 & I & - & - & 5 \\
\hline & 13 & I & - & 1 & 1 & 1 & I & I & - & - & I & I & 1 & - & - & 1 & 10 \\
\hline & 14 & I & 1 & - & - & - & 1 & - & - & - & I & 1 & - & - & - & - & 5 \\
\hline & 15 & 1 & 1 & I & - & I & I & - & I & I & I & I & I & I & 1 & - & 12 \\
\hline & 16 & I & 1 & I & - & 1 & 1 & I & I & 1 & I & - & 1 & 1 & - & 1 & 12 \\
\hline & 17 & I & - & - & - & - & - & I & I & 1 & I & I & - & - & I & 1 & 8 \\
\hline \multirow[t]{6}{*}{ Reliability } & 18 & - & - & - & - & - & - & - & - & - & - & - & - & - & - & - & 0 \\
\hline & 19 & - & - & - & - & - & - & - & - & - & - & - & - & - & - & 1 & 1 \\
\hline & 20 & - & - & - & - & - & - & - & - & - & - & - & - & - & - & - & 0 \\
\hline & 21 & I & - & - & - & I & - & - & - & - & - & - & - & - & - & - & 2 \\
\hline & 22 & - & - & - & - & - & - & - & I & - & - & - & - & - & - & - & I \\
\hline & 23 & - & - & - & - & - & - & I & 1 & 1 & - & - & - & - & - & 1 & 4 \\
\hline \multirow[t]{6}{*}{ Validity } & 24 & - & - & - & - & - & - & - & - & - & - & - & - & - & - & - & 0 \\
\hline & 25 & - & - & - & - & - & - & - & - & - & - & - & - & - & - & 1 & 1 \\
\hline & 26 & - & - & - & - & - & - & - & - & - & - & - & - & - & - & - & 0 \\
\hline & 27 & - & - & - & - & - & - & - & - & - & - & - & - & - & - & - & 0 \\
\hline & 28 & - & - & - & - & - & - & - & - & - & - & - & - & - & - & - & 0 \\
\hline & 29 & - & - & - & - & - & - & - & - & 1 & - & - & - & - & - & 1 & 2 \\
\hline $\begin{array}{l}\text { Confounding } \\
\text { aspects }\end{array}$ & 30 & - & - & 1 & 1 & - & - & - & - & - & 1 & I & I & 1 & - & 1 & 7 \\
\hline Total & & 13 & 9 & 8 & 6 & 10 & 6 & 11 & 9 & 8 & 12 & 8 & 9 & 12 & 5 & 12 & \\
\hline
\end{tabular}

Abbreviations: The assessment items $\mathrm{I}-30$ are fully described in Appendix I. 
Table 2 Breast cancer treatment modalities, late morbidity in relation to ADL/QOL

\begin{tabular}{|c|c|c|c|c|c|c|c|c|c|c|c|c|}
\hline \multirow[t]{2}{*}{ Reference } & \multirow{2}{*}{$\begin{array}{l}\text { Sample size }(n) \\
\text { Dropout rate } \\
(n / \%)\end{array}$} & \multicolumn{5}{|c|}{ Treatment (\%) } & \multirow[t]{2}{*}{ Late morbidity } & \multirow[t]{2}{*}{$\%$} & \multirow[t]{2}{*}{$\begin{array}{l}\text { Assessment method } \\
\text { and follow up }\end{array}$} & \multicolumn{3}{|c|}{$\begin{array}{c}\text { Relationship late morbidity } \\
\text { with } A D L / Q O L\end{array}$} \\
\hline & & $\mathrm{BCT}$ & MRM & $\begin{array}{c}\text { RT+ } \\
\text { CWBR }\end{array}$ & $\mathrm{RT}+\mathrm{N}$ & $\overline{\mathrm{RT}-}$ & & & & & & \\
\hline $\begin{array}{l}\text { Swedborg } \\
\text { et al., } 1981^{43}\end{array}$ & 475 & 0 & 100 & 70 & $70^{(\#)}$ & 30 & $\begin{array}{l}\text { (\#) } \\
\text { Pain } \\
\text { ROM (abduction) } \\
\text { Edema } \\
\text { Grip strength }\end{array}$ & $\begin{array}{l}18 \\
51 \\
15 \\
33\end{array}$ & $\begin{array}{l}\text { Phys exam } \\
\text { VOL/ROM/grip strength } \\
\text { Subjective rating } \\
\text { Discomfort/pain/ADL difficulties } \\
49 M \text { post surgery }\end{array}$ & $\begin{array}{l}\text { Disabilities. } \\
\text { ADL } \\
\text { Household } \\
\quad \text { chores } \\
\text { Appearance } \\
\text { Clothes }\end{array}$ & $\begin{array}{l}\% \text { of } p \\
9 \% \\
50 \% \\
19 \% \\
13 \%\end{array}$ & atients \\
\hline $\begin{array}{l}\text { Segerström } \\
\text { et al., }|99|^{46}\end{array}$ & $\begin{array}{l}100 \\
7(7 \%)\end{array}$ & 0 & 100 & 100 & 57 & 0 & $\begin{array}{l}\text { Pain } \\
\text { ROM } \\
\text { Edema } \\
\text { FI }\end{array}$ & $\begin{array}{l}39 \\
49 \\
43 \\
63\end{array}$ & $\begin{array}{l}\text { Phys exam: VOL/ROM } \\
\text { Questionnaire } \\
\text { Pain/FI } \\
38 \text { M post RT }\end{array}$ & $\begin{array}{l}\text { Edema-FI } \\
\text { ROM-FI }\end{array}$ & & $\begin{array}{l}(P<0.0 \mathrm{I}) \\
(P<0.0 \mathrm{I})\end{array}$ \\
\hline $\begin{array}{l}\text { Maunsel } \\
\text { et al., }|99|^{42}\end{array}$ & $\begin{array}{l}223 \\
22(13 \%)\end{array}$ & 35 & 65 & $?$ & $?$ & $?$ & $\begin{array}{l}\text { Pain } \\
\text { Numbness } \\
\text { ROM } \\
\text { Edema } \\
\text { Strength }\end{array}$ & $\begin{array}{l}51 \\
49 \\
16 \\
24 \\
18\end{array}$ & $\begin{array}{l}\text { Interview } \\
\text { Questionnaire } \\
\text { PSI } \\
\text { I8M post surgery }\end{array}$ & $\begin{array}{l}\mathrm{Nr} \text {, arm } \\
\text { problems and } \\
\text { Psychological } \\
\text { distress }\end{array}$ & & $(P<0.00 \mathrm{I})$ \\
\hline $\begin{array}{l}\text { Tasmuth } \\
\text { et al., } 1996^{50}\end{array}$ & $\begin{array}{l}105 \\
12(11 \%)\end{array}$ & 43 & 57 & 63 & 24 & 37 & $\begin{array}{l}\text { Pain (breast) } \\
\text { Pain (arm) } \\
\text { Numbness } \\
\text { Edema } \\
\text { Grip strength } \\
\text { Phantom sensation }\end{array}$ & $\begin{array}{l}23 \\
17 \\
80 \\
38 \\
17 \\
25\end{array}$ & $\begin{array}{l}\text { Phys exam } \\
\text { ROM/grpi strength } \\
\text { Questionnaire } \\
\text { VAS (pain), STAI/depression } \\
\text { I } 2 \text { M post surgery }\end{array}$ & $\begin{array}{l}\text { Pain-ADL } \\
\text { Chronic } \\
\text { symptoms } \\
\text { and anxiety/ } \\
\text { depression }\end{array}$ & & $\begin{array}{l}(P<0.0 \mathrm{I}) \\
(P<0.00 \mathrm{I})\end{array}$ \\
\hline $\begin{array}{l}\text { Sugden et al., } \\
1998^{41}\end{array}$ & $\begin{array}{l}14 \mid \\
14(10 \%)\end{array}$ & 72 & 28 & 100 & 35 & 0 & $\begin{array}{l}\text { Pain } \\
\text { Numbness } \\
\text { ROM } \\
\text { Edema: subj } \\
\quad \text { obj }\end{array}$ & $\begin{array}{r}12 \\
51 \\
48 \\
29 \\
6\end{array}$ & $\begin{array}{l}\text { Interview } \\
\text { Phys exam } \\
\text { Functional assessment } \\
\text { I8M post RT }\end{array}$ & $\begin{array}{l}\text { Treatment } \\
\text { and } A D L \\
\text { disabilities: } \\
\text { MRM }<\text { BCT } \\
\text { (dressing) }\end{array}$ & & \\
\hline $\begin{array}{l}\text { Hack et al., } \\
1999^{54}\end{array}$ & $\begin{array}{l}248 \\
26(11 \%)\end{array}$ & 64 & 36 & 61 & 0 & 39 & $\begin{array}{l}\text { State paid } \\
\text { Pain/ROM } \\
\text { Numbness } \\
\text { Strength }\end{array}$ & $\begin{array}{l}31 \\
73 \\
63 \\
18\end{array}$ & $\begin{array}{l}\text { Phys exam: ROM } \\
\text { Questionnaire } \\
\text { Pain: MPPQ/SF-MPQ/PDI } \\
\text { EORTC QLC-C30/MHI } \\
33 \pm 23 \text { M post surgery }\end{array}$ & $\begin{array}{l}\text { Pain related } \\
\text { disability } \\
\text { Pain and } \mathrm{QOL} \\
\text { Pain and } \mathrm{MH}\end{array}$ & $57 \%$ & $\begin{array}{l}(P<0.00 \mathrm{I}) \\
(P<0.00 \mathrm{I})\end{array}$ \\
\hline
\end{tabular}

Abbreviations: $\mathrm{BCT}=$ breast conservative treatment; $M R M=$ modified radical mastectomy; $\mathrm{RT}+=$ radiation therapy; $\mathrm{RT}-=$ no radiation therapy; $\mathrm{CWBR}=$ chest wall/breast;

$\mathrm{N}=$ axillary nodes; $\mathrm{ADL}=$ activities of daily living, $\mathrm{QOL}=$ quality of life; phys exam = physical examination; subj $=$ subjective; obj = objective; $\mathrm{VOL}=\mathrm{volume} ; \mathrm{ROM}=$ range of $\mathrm{motion}$, $M=$ month; $\mathrm{FI}=$ functional impairment; $\mathrm{PSI}=$ psychiatric symptom index; $\mathrm{nr}=$ number; $\mathrm{STAl}=$ state and trait anxiety; $\mathrm{MPPQ}=$ modified post-operative pain questionnaire;

SF-MPQ = short-form McGill pain questionnaire; PDI = pain disability index; EORTC QLQ-C30 = The European Organization for Research and Treatment of Cancer Quality of Life

Questionnaire; $\mathrm{MHI}=$ mental health inventory, $\mathrm{MH}=$ mental health.

\# These data were abstracted from an article referred to (Swedborg et al., 1981). ${ }^{38}$ 
was 30. None of the selected articles received the maximum score. The highest score obtained was 13 by Swedborg et al. ${ }^{43}$ Six out of the 15 articles reached a score of one-third (10) of the maximum score. The general methodological aspect of the studies (items I-I I and 30) scored moderate within these articles. In 14 articles there was a clear description of inclusion criteria. However, exclusion criteria were only mentioned in four articles. In most studies the study design was prospective or at least longitudinal. Only two studies accomplished the criteria of a randomized control study. In nine of the studies a stratified analysis was applied. The extent of the surgical procedure was more frequently described ( 10 times) as compared to the extent and dose of the radiation therapy (seven times). Adjunctive treatments such as chemotherapy or hormonal therapy were reported in seven articles. Eleven articles reported the number of dropouts. In two studies a pretreatment baseline assessment was performed. ${ }^{41,50}$ All articles described the measurement instruments used (items 12-17). Most frequently these instruments assessed pain, lymph edema or functional performance (items 13, 15 and 16). In only five articles, instruments to assess range of motion or strength were used. The items reliability and validity of the measurement instruments (items 18-29) scored poorly. Six articles fulfilled some of these items. Out of the measurement instruments, reliability of QOL questionnaire had the highest score with a positive assessment within four articles.

As mentioned, six articles fulfilled ten or more of the methodological criteria (Swedborg et al., 1981, ${ }^{43}$ Segerström et al., 1991, ${ }^{46}$ Maunsell et al., 1992, ${ }^{49}$ Tasmuth et al., 1996, ${ }^{50}$ Sugden et al., 1998, ${ }^{41}$ Hack et al., 199954) and these articles will be discussed in more detail (Table 2).

The surgical treatment modalities described in these six articles were modified radical mastectomy or breast conserving treatment both with axillary clearance. Only in the article of Maunsell et al., 1992 it was reported that $7 \%$ of the patients had no axillary clearance. ${ }^{49}$ In the two earliest articles, only modified radical mastectomy with axillary clearance was applied. ${ }^{43,46}$ In the two most recent studies two-third of the patients had a breast conserving treatment. ${ }^{41,54}$ Radiation therapy was applied in all studies on chest wall or breast covering the parasternal and supraclavicular nodes and adjuvantly at the axillary nodes in four of the studies. ${ }^{41,43,46,50}$ In one article the radiation therapy was not specified. ${ }^{49}$

\section{Late morbidity}

Pain

All six studies assessed the incidence of pain. The assessment instruments varied from self-constructed questionnaires, subjective rating scales and VAS scores to validated pain questionnaires. One study used three different instruments to assess pain. ${ }^{54}$ The prevalence of pain one year or later after treatment of breast cancer ranged from 12-51\% between the studies. No significant relationship was found between pain perception and the type of breast surgery (conservative or amputation) and radiation therapy. ${ }^{41,50,54}$ One author found a significant relationship between pain, age, number of axillary nodes dissected and chemotherapy. ${ }^{54}$ Factors increasing pain were sleeping on the operated side, reaching out, carrying, working with the arm, housework and handicraft. ${ }^{50}$

It was found that the incidence of pain increased from 23 to $39 \%$ in the follow up from 14 to 38 months after treatment. ${ }^{46}$ However, others found a decrease in the incidence of pain 6 to 12 months after treatment ${ }^{50}$ or did not found a relationship to the time elapsed since the treatment. $^{54}$ Thus no clear relationship between pain and follow up period after treatment can be deduced from the reviewed articles.

\section{Range of motion}

The assessment of the range of motion of the arm was performed by physical examination ${ }^{41,43,46,50,54}$ or a subjective rating by the patient. ${ }^{49} \mathrm{~A}$ goniometer was used only in one article. ${ }^{4 \mathrm{I}}$ Maunsell et al. assessed the range of motion by letting choose the patient from five images representing the capacity to lift the arm through a $180^{\circ}$ range. ${ }^{49}$ Abduction of the shoulder was assessed in all studies.

The prevalence of restricted range of motion of the affected arm varied from 2 to $51 \%$ of the patients. A severe reduction of the range of motion (more than $50 \%$ reduction) was found in $2 \%$ of the patients. ${ }^{43}$ The mobility of the shoulder was significantly less for the patients receiving radiotherapy on the axilla. ${ }^{41,43}$ Range of motion was significantly smaller in the patients with mastectomy as compared with patients with a breast conserving treatment. ${ }^{41}$

\section{Edema}

Swelling of the affected arm was assessed in five studies. Different methods were used. Two studies used the 'water displacement method', 43,46 two studies used the circumference method $^{41,50}$ and one ${ }^{49}$ used a questionnaire to assess perceived problems as a result of edema. Different criteria for edema were used. Edema of the arm was defined as a volume difference between the arms of more than $10 \%{ }^{43}$ or $150 \mathrm{ml},{ }^{46}$ an increase of the circumference of the affected arm on two sites of at least $2 \mathrm{~cm}$ compared to the preoperative circumference ${ }^{50}$ or a relative arm circumference value of more than $110 \%$ compared to the contralateral arm. ${ }^{41}$ The prevalence of arm edema varied from 6-43\%. Patients with mastectomy had significantly more frequently edema as compared to patients with breast conserving 
treatment. ${ }^{41,50}$ Edema of the arm correlated significantly with axillary lymph node dissection and receiving radiotherapy. ${ }^{43,49}$

\section{Strength}

Muscle strength of the arm at the treated side of the patients was assessed in four studies. The assessment method varied from physical assessment of grip strength $^{43,50}$ to subjective reported weakness. ${ }^{49,54}$ The prevalence of strength reduction ranged between 17 and $33 \%$. The decrease in grip strength is significantly greater if the dominant side had been operated as compared with the non-dominant side. ${ }^{50}$

\section{Activities of daily life and quality of life}

All studies assessed although in different ways the relationship between the late morbidity and ADL and QOL. The assessment instruments used, varied from self-constructed questionnaires, subjective rating scales concerning performed $\mathrm{ADL}$ to reliable and valid questionnaires (Table 2). None of the six selected articles described valid or reliable instruments for assessment of ADL. Only one author used a reliable and validated instrument; the pain disability index (PDI) to assess pain related disabilities. ${ }^{54}$ Four studies assessed some aspects of QOL, but only one study used a valid and reliable instrument; the European organization for research and treatment of cancer quality of life questionnaire (EORTC QLQ-C30). ${ }^{54}$

\section{Relationship of late morbidity to $A D L$}

A significant relationship was reported between edema and restricted range of motion and patients own assessment of functional impairments. ${ }^{46}$ Although $9 \%$ of the patients showed some restriction in daily life activities through edema, $50 \%$ reported interference of their swollen arm with household chores. ${ }^{43}$ One author used a scale, which contained ten functions of daily independent living to assess functional ability. ${ }^{4}$ Patients with a mastectomy reported more problems as compared to patients with a breast-conserving treatment. Functions of ADL giving difficulties for both groups were: pulling sweater over head (20\%), fasten bra (18\%), doing up back zipper (72\%), reaching over head (16\%) and carrying heavy bags (29\%). ${ }^{41}$ ADL such as sleeping on the operated side, reaching out, working with the ipsilateral arm, housework or handicraft are significantly correlated with perceived aggravation of chronic post-treatment pain intensity. ${ }^{50}$

\section{Relationship of late morbidity to quality of life}

The number of perceived arm problems 18 months after treatment of breast cancer was significantly associated with high psychological distress assessed in Psychiatric Symptom Index. ${ }^{49}$ Compared with women reporting no problems in the affected arm due to late morbidity, the adjusted odds ratios for having substantial psychological distress in women reporting one or two, three or four and five to six arm problems were I.9, 4.4 and 6.I respectively $\left(\chi^{2}\right.$ for trend $\left.=14.0, P=0.0002\right) .{ }^{49}$ Women who had axillary dissection reported significantly more arm problems due to late morbidity.

The number of symptoms reported preoperatively and the number of chronic symptoms of late morbidity in the operated side correlated significantly with the level of anxiety and depression. ${ }^{50}$ One author investigated the physical and psychological morbidity after axillary lymph node dissection using the EORTC QOLQ-C30.54 Overall, just about half of the patients experienced pain-related discomfort and disability. The QOL and mental health of the patients were generally good. Regression analysis showed a significantly negative association between patients subjective reports of pain and the QOL. The disabling impact of their pain on selfcare, sexual activities and general arm motion predicted a poorer mental health. ${ }^{54}$

\section{DISCUSSION}

In the last 20 years only a few studies investigated the relationship between late morbidity of the upper limb one year or later after treatment of early breast cancer and the perceived disabilities and/or QOL. ${ }^{30,39,41,43-54} \mathrm{~A}$ systematic literature search revealed 15 articles out of 1642 articles. The methodological quality of these 15 articles was poor. Only 6 of the 15 articles fulfilled one third of our criteria. The checklist applied in this review consisted of two parts, one concerning general methodological aspects of studies and one concerned assessment instruments and their reliability and validity. If we skipped the criteria covering reliability and validity of applied assessment instruments and used the same relative cut off point, 14 articles would be included. However, we set a high standard and justify this choice as follows: if a relation between impairments and disability and/or QOL is found, it must be clear that these conclusions depend on outcomes of reliable and valid assessment instruments. Because of the differences in the assessment techniques used for the impairments as well for the disabilities and/or QOL and because of the poor methodology, no meta analysis could be performed.

To analyze the interobserver agreement, all the selected articles were assessed by two reviewers independently. After exclusion of seven items of the methodological checklist which scored constant and thus may give an artificial high overall Cohen's Kappa, the measure of agreement remained high (overall Cohen's Kappa: 0.87). 
Only two studies, Swedborg et al. and Aitken et al. described the design of a randomized clinical trial. ${ }^{39,43}$ However, in relation to the topic of this systematic review the type of study design is of less importance. Surprisingly only two studies applied a pretreatment baseline measurement. ${ }^{41,50}$ In our opinion this baseline measurement is of considerable importance to assess a point of departure by which the later measurements can be compared.

\section{Assessment of late morbidity}

As mentioned earlier a great variability in the applied assessment instruments for impairments was found. In addition, no uniform criteria exist for impairments in pain, range of motion, volume or muscle strength. This lack of criteria may partly explain the variation in prevalence of pain (12-51\%), impairment of range of motion (2-5I\%), edema (6-43\%) and decreased strength (17-33\%). ${ }^{41,43,46,49,50,54}$ The different treatment modalities in the selected studies may also attribute to the variation in prevalence of impairments, as was found by Sugden et al. who reported that patients with a mastectomy had significant more restrictions in range of motion and edema compared to patients with a wide local excision. ${ }^{4 l}$

\section{Assessment of ADL and/or quality of life}

Also a wide variability in assessment instruments for ADL was found. The lack of uniformity and reliability/ validity of these instruments weakened the validity of the results of the different studies. Additionally comparison of the results is very difficult. Only four articles assessed some aspects of QOL. ${ }^{43,49,50,54}$ It seems that QOL is valued poorly in studies concerning the treatment for early breast cancer. However this impression may be the result of our selection criteria.

\section{Late morbidity (impairments) in relation to $A D L$ and/or $Q O L$}

The six articles reviewed, reported relationship between the treatment of early breast cancer related impairments of the upper limb and perceived disabilities and/or QOL. Although the reported relationships were significant in four of the articles, the clinical relevance of this relationship is not clear. The data of Segerström et al. show a rather low relative risk between the presence of edema of the arm and the assessment of functional impairments $(R R=1.6){ }^{46}$ The same $R R(1.6)$ can be calculated for the presence of restricted range of motion and estimated functional impairments. ${ }^{46}$ However, detailed description of these functional impairments is not given. A more detailed description of perceived problems of several ADL was given by Sugden et al. ${ }^{4 I}$ The significant difference in prevalence of late morbidity between the two treatment groups (mastectomy and wide local excision) was also reflected in these perceived problems of ADL. But the author did not provide the strength of the relationship between late morbidity and perceived problems of ADL. An inverse relationship between the performance of $A D L$ and aggravating pain was reported by Tasmuth et al. ${ }^{50}$

Although a significant relationship was reported, the strength of the relationship was not described. Other results were reported by Maunsell et al. who found a strong relationship between the reported number of perceived arm problems and a high psychiatric symptom index. ${ }^{49}$ The adjusted odds ratios for having substantial psychological distress in women reporting one or two, three or four and five to six arm problems were I.9, 4.4 and 6.1 respectively $\left(\chi^{2}\right.$ trend $\left.=14.0\right)$.

Hack et al. reported a relationship between subjective reported pain and $\mathrm{QOL}$ but also in this study the explained variance was weak $\left(r^{2}=14 \%\right){ }^{54}$ Late morbidity was associated with axillary lymph node dissection and with axillary radiation therapy. ${ }^{41,43,49,54}$ These results may indicate an association between axillary lymph node dissection and/or axillary radiation therapy with poorer QOL. But the strength of this association is unclear.

\section{CONCLUSION}

In the last 20 years (1980-1999) only a few studies investigated the relationship between late morbidity of the upper limb one year or later after treatment of early breast cancer and the perceived disabilities and/or QOL. The overall methodological quality of these articles was limited. Little attention was paid to reliability and validity of the assessment tools. Six articles fulfilled one third of the estimated methodological criteria.

These six articles described significant relationship between late morbidity after treatment of early breast cancer and restrictions of daily activities and poorer QOL. However, the strength of this relationship is overall low or not given. Clinical relevance of the relationship is up till now poorly investigated.

\section{REFERENCES}

I. Visser O, Coebergh JWW, Schouten LJ, van Dijck JAAM. Incidence of cancer in the Netherlands 1997, ninth report of the Netherlands Cancer Registry. Utrecht. NCR $200 \mathrm{I}$.

2. Greenlee RT, Hill-Harmon MB, Murray T, Thun M. Cancer statistics, 200 I. Cancer J Clin 200 I; 5 I: I5-36.

3. Levi F, Lucchini F, Negri E, La Vecchia C. The decline in cancer mortality in the European Union, 1988-1996. Eur J Cancer 2000; 36: 1965-8.

4. Halsted WS. Swelling of the arm after operations for cancer of the breast - Elephantiasis chirurgica - its causes and prevention. Bull Johns Hopkins Hosp 1921; 32: 309-13.

5. Brismar B, Ljungdahl I. Postoperative lymphedema after treatment of breast cancer. Acta Chir Scand 1983; 149: 687-9.

6. Kissin MW, Querci della Rovere G, Easton D, Westbury G. Risk of lymfoedema following the treatment of breast cancer. $\mathrm{Br} J$ Surg 1986; 74: 580-4. 
7. Nikkanen TAV, Vanharante $H$, Helenius-Reunanen $H$. Swelling of the upper extremity, function and muscle strength of shoulder joint following mastectomy combined with radiotherapy. Ann Clin Res 1978; 10: 273-9.

8. Yeoh EK, Denham JW, Davies SA, Spittle MF. Primary breast cancer; complications of axillary management. Act Radiat Oncol 1986; 25: 105-8.

9. Madden JL, Kandalaft S, Bourque RA. Modified radical mastectomy. Ann Surg 1972; 175: 624-34.

10. McWhirter $\mathrm{R}$. The role of simple mastectomy and radiotherapy in the treatment of cancer of the breast. $\mathrm{Br} J$ Radiol 1948; 2 I: 599-610.

II. Fisher B, Wolmark N, Redmond C, Deutsch M, Fisher ER Findings from NSABP Protocol No B-04. Comparison of radical mastectomy with alternative treatments. Cancer $|98| ; 48$ : 1863-72.

12. Forrest APM, Stewart HJ, Roberts M, Steele RJC. Simple mastectomy and axillary node sampling (pectoral node biopsy) in the management of primary breast cancer. Ann Surg 1982; I 96: 37I-7.

13. Brismar B, Ljungdahl I. Postoperative lymphoedema after treatment of breast cancer. Act Chir Scand 1983; 149: 687-9.

14. Almaric R, Santamaria F, Robert F et al. Radiation therapy with or without primary limited surgery for operable breast cancer: a 20-year experience at the Marseille Cancer Institute. Cancer 1982 49: $30-4$.

I5. Veronesi U, Saccozzi R, Del Vecchio $M$ et al. Comparing radical mastectomy with quandrantectomy, axillary dissection, and radiotherapy in patients with small cancers of the breast. $N$ Engl J Med 1981; 305: 6-II.

16. Fisher B, Anderson S, Redmond CK, Wolmark N, Wickerham DL, Cronin WM. Reanalysis and results after 12 years of follow-up in a ransomized clinical trial comparing total mastectomy with lumpectomy with or without irradiation in the treatment of breast cancer. N Engl J Med 1995; 333: |456-6I.

17. Kurtz JM, Kinkel K. Breast conservation in the 2 lst century. Review. Eur J Cancer 2000; 36: 1919-24.

18. Calle R, Pilleron JP. Radiation therapy with or without lumpectomy for operable breast cancer. Breast 1979; 5: 2-6.

19. Clark RM, Wilkinson RH, Mohoney LJ, Reid JC, McDonald WD. Breast cancer: a 21 experience with conservative surgery and radiation. Int J Radiat Oncol Biol Phys 1982; 8: 967-75.

20. Delouche G, Bachelot F. Tumorectomie et radiothérapie pour les petit cancers du sein opérables d'emblée. J Eur Radiother 1980; 3: $|3|-8$.

2I. Delouche G, Bachelot F, Premont M, Kurtz JM. Conservation treatment of early breast cancer: long term results and complications. Int J Radiat Oncol Biol Phys 1987; 13: 29-34.

22. Montague ED. Experience with altered fractionation in radiation therapy of breast cancer. Radiology 1968; 90: 962-6.

23. Gerber L, Lampert M, Wood C et al. Comparison of pain, motion and edema after modified radical mastectomy vs. local excision with axillary dissection and radiation. $\mathrm{Br}$ Cancer Res Treatment 1992; 2 I: 139-45.

24. Thomson AM, Air M, Jack WJL, Kerr GR, Rodger A, Chetty U. Arm morbidity after breast conservation and axillary therapy. The Breast 1995; 4: 273-6.

25. Moffat FL, Senofsky GM, Davis K et al. Axillary node dissection for early breast cancer: some is good, but all is better. J Surg Oncol 1992; 51: 8-13.

26. Donegan WL. Prognostic factors: stage and receptor status in breast cancer. Cancer 1992; 70: 1755-64.

27. Recht A, Houlihan MJ. Axillary lymph nodes and breast cancer; a review. Cancer 1995; 76: 149I-5I2.

28. Liljegren G, Holmberg L. Arm morbidity after sector resection and axillary dissection with or without postoperative radiotherapy in breast cancer stage I. Results from a randomised trial. Eur J Cancer 1997; 33: 193-9.

29. Hladiuk M, Huchcroft S, Temple W, Schnurr BE. Arm function after axillary dissection for breast cancer: a pilot study to provide parameter estimates. J Surg Oncol 1992; 50: 47-52.

30. Bentzen SM, Overgaard M, Thames HD. Fractionating sensitivity of a functional endpoint: impaired shoulder movement after postmastectomy radiotherapy. Int I Radiat Oncol Biol Phys 1989; I 7 : $531-7$.
31. Pezner RD, Patterson MP, Hill LR et al. Arm oedema in patients treated conservatively for breast cancer: relationship to patients age and axillary node dissection techniques. Int J Radiat Oncol Biol Phys 1986; 12: 2079-83.

32. Giuliano AE, Dale PS, Turner RR, Morton DL, Evans SW, Krasne DL. Improved axillary staging of breast cancer with sentinel lymphadenectomy. Ann Surg 1995; 222: 394-9.

33. Veronesi U, Paganelli G, Galimberti V et al. Sentinel-node biopsy to avoid axillary dissection in breast cancer with clinically negative lymphnodes. Lancet 1997; 349: 1864-7.

34. Ollila DW, Brennan MB, Giuliano AE. The role of intraoperative lymphatic mapping and sentinel lymphadenectomy in the management of patients with breast cancer. In: Advances in Surgery Vol. 32. Mosby, Inc., 1999: 349-64.

35. Schrenk P, Rieger R, Shamiyeh A, Wayand W. Morbidity following sentinel lymphnode biopsy versus axillary lymphnode dissection for patients with breast carcinoma. Cancer 2000; 88: 608-14.

36. Ryttov N, Blichert-Toft M, Madsen EL, Weber J. Influence of adjuvant irradiation on shoulder joint function after mastectomy for breast carcinoma. Act Radiat Oncol 1983; 22: 29-33.

37. Ryttov N, Holm NV, Qvist N, Blichert-Toft $M$. Influence of adjuvant irradiation on the development of late arm lymphedema and impaired shoulder mobility after mastectomy for carcinoma of the breast. Act Oncol 1988; 27: 667-70.

38. Swedborg I, Wallgren A. The effect of pre- and postmastectomy radiotherapy on the degree of edema, shoulder-joint mobility and gripping force. Cancer I98I; 47: 877-8I.

39. Aitken RJ, Gaze MN, Rodger A, Chetty U, Forrest APM. Arm morbidity within a trial of mastectomy and either nodal sample with selective radiotherapy or axillary clearance. Br J Surg 1989; 76: 568-7I.

40. Wallgren A. Late effects of radiotherapy in the treatment of breast cancer. Acta Oncol 1992; 3 I: 237-42.

4I. Sugden EM, Rezvani M, Harrison JM, Hughes LK. Shoulder movement after the treatment of early stage breast cancer. Clin Oncol 1998; 10: 173-8I.

42. Bruner DW, Wasserman T. The impact on quality of life by radiation late effects. Int J Radiat Oncol Biol Phys 1995; 3 I: I353-5.

43. Swedborg I, Borg G, Sarnelid M. Somatic sensation and discomfort in the arm of post-mastectomy patients. Scand J Rehab Med 198I; 13: 23-9.

44. Tobin MB, Psych MRC, Lacey HJ, Meyer L, Mortimer PS. The Psychological morbidity of breast cancer-related arm swelling. Cancer 1993; 72: 3248-53.

45. Hamilton CS, Nield JM, Adler GF, Clingan PR. Breast appearance and function after breast conserving surgery and radiotherapy. Act Oncol 1990; 29: 29l-5.

46. Segerström K, Bjerle $P$, Nyström $\AA$. Importance of time in assessing arm and hand function after treatment of breast cancer. Scand J Plast Reconstr Hand Surg 199I; 25: 24I-4.

47. Sneeuw KCA, Aaronson NK, Yarnold JR, Broderick M, Regan J, Ross G, Goddard A. Cosmetic and functional outcomes of breast conserving treatment for early stage breast cancer. 2. Relationship with psychosocial functioning. Radiother Oncol 1992; 25: I60-6.

48. Ivens D, Hoe AL, Podd T], Hamilton CR, Taylor I, Royle GT. Assessment of morbidity from complete axillary dissection. $\mathrm{Br} J$ Cancer 1992; 66: 136-8.

49. Maunsell E, Brisson J, Deschènes L. Arm problems and psychological distress after surgery for breast cancer. Can J Surg 1992; 36: 315-20.

50. Tasmuth T, Smitten von K, Kalso E. Pain and other symptoms during the first year after radical and conservative surgery for breast cancer. Br J Cancer 1996; 74: 2024-3I.

5I. Carpenter JS, Andrykowski MA, Sloan P et al. Postmastectomy/ postlumpectomy pain in breast cancer survivors. J Clin Epidemiol 1998; 5 I: 1285-92.

52. Warmuth MA, Bowen G, Pronitz LR et al. Complications of axillary lymph node dissection for carcinoma of the breast. Cancer 1998; 83: 1362-8.

53. Velanovich V, Szymanski W. Quality of life of breast cancer patients with lymphedema. Am J Surg 1999; 177: 184-8.

54. Hack TF, Cohen L, Katz J, Robson LS, Goss P. Physical and psychological morbidity after axillary lymph node dissection for breast cancer. J Clin Oncol 1999; I7: 143-9. 


\section{APPENDIX I}

Criteria list for the assessment of the methodological quality of the selected studies.

\section{Study population}

I. The study received I point if there is a clear description of inclusion criteria.

2. The study received I point if exclusion criteria were described.

\section{Study design}

3. The study received I point if the design is longitudinal.

4. The study received I point if the design is prospective.

5. The study received I point if it is a randomized control study.

\section{Allocation procedure}

When it is a randomized control study; the randomization procedure is adequate

6. The study received I point if concealed allocation and random sequence generation is applied.

\section{When it is a cohort study; the matching procedure is adequate}

7. The study received I point if the treatment groups are comparable according to two following criteria; age and the pretreatment morbidity status or a stratified analysis is applied.

\section{Description of the treatments}

8. The study received I point if there is a clearly description of the extent of surgical procedure in the various groups.

9. The study received I point if there is a clearly description of the daily radiation dose and localization.

\section{Dropouts description}

10. The study received I point if the number of dropouts is described.

\section{Measurement}

II. The study received I point if a pretreatment baseline measurement is performed.

\section{Measurement instruments}

12. The study received I point if a measurement instrument to assess the range of motion of the shoulder joint was used.
13. The study received I point if a measurement instrument to assess perceived pain was used.

14. The study received I point if a measurement instrument to assess strength of the upper limb was used.

15. The study received I point if for using a measurement instrument to assess lymph edema of the upper limb was used.

16. The study received I point if a measurement instrument to assess the functional performance/ perceived disabilities was used.

17. The study received I point if a measurement instrument to assess the quality of life was used.

\section{Reliability}

18. The study received I point if reliability of instrument(s) measuring range of motion, has been reported by the authors or has been established in studies cited by the authors.

19. The study received I point if reliability of instrument(s) measuring perceived pain, has been reported by the authors or has been established in studies cited by the authors.

20. The study received I point if reliability of instrument(s) measuring strength has been reported by the authors or has been established in studies cited by the authors.

21 . The study received I point if reliability of instrument(s) measuring lymph edema of the arm has been reported by the authors or has been established in studies cited by the authors.

22. The study received I point if reliability of instrument(s) measuring functional performance/ perceived disabilities has been reported by the authors or has been established in studies cited by the authors.

23. The study received I point if reliability of instrument(s) measuring quality of life has been reported by the authors or has been established in studies cited by the authors.

\section{Validity}

24. The study received I point if validity of instrument(s) measuring range of motion, has been reported by the authors or has been established in studies cited by the authors.

25. The study received I point if validity of instrument(s) measuring perceived pain, has been reported by the authors or has been established in studies cited by the authors.

26. The study received I point if validity of instrument(s) measuring strength, has been reported by the authors or has been established in studies cited by the authors. 
27. The study received I point if validity of instrument(s) measuring lymph edema of the arm, has been reported by the authors or has been established in studies cited by the authors.

28. The study received I point if validity of instrument(s) measuring functional performance/ perceived disabilities, has been reported by the authors or has been established in studies cited by the authors.
29. The study received I point if validity of instrument(s) measuring quality of life, has been reported by the authors or has been established in studies cited by the authors.

\section{Confounding aspects}

30. The study received I point if adjunctive treatments are reported. 